NREL/CP-5500-55044. Posted with permission.

Proceedings of the ASME 2012 6th International Conference on Energy Sustainability \& 10th Fuel Cell Science, Engineering and Technology Conference

ESFuelCell2012

July 23-26, 2012, San Diego, CA, USA

ESFuelCell2012-91317

\title{
A DIRECT-STEAM LINEAR FRESNEL PERFORMANCE MODEL FOR NREL'S SYSTEM ADVISOR MODEL
}

\author{
Michael J. Wagner \\ National Renewable Energy Laboratory \\ Golden, Colorado 80401 \\ Email: michael.wagner@nrel.gov
}

\author{
Guangdong Zhu \\ National Renewable Energy Laboratory \\ Golden, Colorado 80401
}

\begin{abstract}
This paper presents the technical formulation and demonstrated model performance results of a new direct-steamgeneration (DSG) model in NREL's ${ }^{1}$ System Advisor Model (SAM). The model predicts the annual electricity production of a wide range of system configurations within the DSG Linear Fresnel technology by modeling hourly performance of the plant in detail. The quasi-steady-state formulation allows users to investigate energy and mass flows, operating temperatures, and pressure drops for geometries and solar field configurations of interest.

The model includes tools for heat loss calculation using either empirical polynomial heat loss curves as a function of steam temperature, ambient temperature, and wind velocity, or a detailed evacuated tube receiver heat loss model. Thermal losses are evaluated using a computationally efficient nodal approach, where the solar field and headers are discretized into multiple nodes where heat losses, thermal inertia, steam conditions (including pressure, temperature, enthalpy, etc.) are individually evaluated during each time step of the simulation.

This paper discusses the mathematical formulation for the solar field model and describes how the solar field is integrated with the other subsystem models, including the power cycle and optional auxiliary fossil system. Model results are also presented to demonstrate plant behavior in the various operating modes.
\end{abstract}

\section{NOMENCLATURE}

CLFR Compact Linear Fresnel Reflector

\footnotetext{
${ }^{1}$ The Alliance for Sustainable Energy, LLC (Alliance), is the manager and operator of the National Renewable Energy Laboratory (NREL). Employees of the Alliance, under Contract No. DE-AC36-08GO28308 with the U.S. Dept. of Energy, have authored this work. The United States Government retains and the publisher, by accepting the article for publication, acknowledges that the United States Government retains a non-exclusive, paid-up, irrevocable, worldwide license to publish or reproduce the published form of this work, or allow others to do so, for United States Government purposes.
}

CSP Concentrating Solar Power

DNI Direct Normal Irradiance

DOE Department of Energy (US)

DSG Direct Steam Generation

HTF Heat Transfer Fluid

IAM Incidence Angle Modifier

IRR Internal Rate of Return

LCOE Levelized Cost of Energy

LF Linear Fresnel

NREL National Renewable Energy Laboratory

OT Once-Through

RC Recirculated

SAM System Advisor Model

TOD Time Of Dispatch

\section{INTRODUCTION}

Linear Fresnel (LF) is an emerging concentrating solar power technology with potential markets in standalone utilityscale electricity generation, process heat, and fossil plant hybridization [1] in the US and internationally. With growing interest from utilities, several technology developers are working to provide commercial products using the LF concept, including Areva (US, France), Novatec Solar (Germany, US), MAN/Ferrostaal (Germany), Industrial Solar (Germany), Fera (Italy) and CNIM (France) [2]. Utilities that are pursuing CSP as an option for meeting renewable portfolio standards stand to benefit from an impartial third party analysis tool that facilitates policy and technology adoption decisions. NREL, in conjunction with Sandia National Laboratory and the US Department of Energy, develop System Advisor Model (SAM) [3] to address this need for a range of renewable technologies, including CSP. The Electric Power Research Institute (EPRI), representing the research interests of utilities and power producers, worked with NREL to develop a performance tool for SAM that is capable of predicting power output for currently marketed LF systems. 


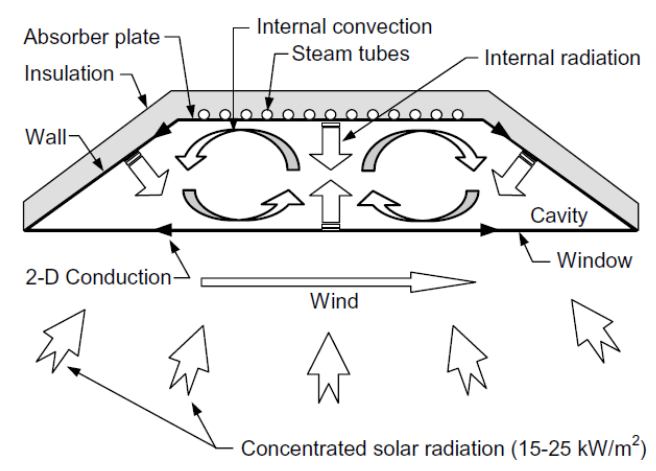

FIGURE 1. Illustration of trapezoidal cavity receiver with associated energy flows, one possible receiver configuration. Source [10].

The SAM LF model primarily seeks to answer the question of project economic viability; given a particular climate, technology configuration, and cost/financial constraints, will a project prove profitable in a local market? The model achieves this goal using detailed annual simulations at hourly time steps, a range of inputs to configure the technology, and realistic financial models that predict LCOE, IRR, and other metrics of interest.

\section{Review of existing models}

A number of Linear Fresnel models have been described previously in literature and vary in detail from simplified to complex component performance models. A brief discussion is provided to review these models and differentiate the SAM LF model from others.

Models used to predict the performance of LF concentrators and receivers have been developed by Goswami, et al. [4], Abbas, et al. [5, 6], Facão, et al. [7], Flores-Larsen, et al. [8], and by a group at the University of New South Wales, Australia, investigating the behavior of trapezoidal cavity receivers $[9,10]$, as illustrated in Figure 1. These papers led the way in establishing the thermal performance of LF receivers and reflectors but do not focus on providing annual simulation tools for techno-economic analysis. In some cases, such models are developed and used for analysis but are not made public or are not easily reusable.

Work by Mills and Morrison [11] investigates a LF configuration using a rack-arranged evacuated tube receiver assembly, similar to those used in high-performance solar hot water applications. Model results are presented assuming operation of this system as a boiler with no option for superheat. One result from this work was extension of the solar hot water library TRNAus for use with LF in the TRNSYS simulation environment [12], though the work is limited to the receiver and solar field configuration described in Mills \& Morrison.

A number of studies are available in literature that compare the performance of Linear Fresnel to parabolic trough [2, 13-15] and power tower [16] technologies. These models make use of annual electricity production codes, though model availability is generally limited or requires reconstruction of desired plant configurations using libraries of subcomponents. This is the case for Morin, et al., and Häberle, et al., who use the ColSim [17] process simulation environment, and for Giostri, et al., who use Thermoflex [18] to model their plant. While modeling plant perfor- mance in a detailed process simulation environment such as ColSim, Thermoflex, or IPSEPro provides the user with a high degree of flexibility and detail, the models also require expert users and significant setup time. Because these tools are not designed for transient simulation, they often require post-processing for startup/shutdown effects and long simulation times for annual calculations of several hours, though simulation time can be reduced by using model simplifications.

The model most similar to SAM is greenius [19], developed by DLR (Germany). The LF model is formulated as an extension of the parabolic trough model, modifying the incidence angle modifier (IAM) table to include both longitudinal and transversal plane effects. The model assumes a sensible-heat HTF similar to the trough formulation, though specific heat can be adjusted to simulate a configuration with lower thermal inertia [20]. A free version of greenius is publicly available, though it restricts access to some parameters and excludes some technologies that are available in the full version.

\section{SAM Model Overview}

Given the existing tools available for modeling Linear Fresnel, we find that a publicly available annual electricity generation model for DSG has not yet been put forward. The new SAM LF model fills this role, addressing this modeling need for the growing LF market in the US. The main features of the SAM LF model are summarized as follows.

Annual-Hourly Simulation SAM uses hourly weather files in typical meteorological year (TM2, TM3), EnergyPlus, or user-generated format. An annual simulation consists of a series of quasi-steady-state hourly calculations, where each simulation time step depends on instantaneous weather conditions and the state of the plant subsystems in the previous time steps.

This formulation allows SAM to capture transient effects, such as behavior during startup and shutdown, and thermal inertia associated with the HTF, piping, and equipment. The user can specify a desired thermal inertia coefficient to adjust how quickly the plant warms and cools during inactive periods and solar resource disruptions. The dependence of the various solar field temperatures is described in more detail in the Mathematical Description section below.

Steam Flow Configuration The SAM LF model includes options for recirculated (RC) and once-through (OT) steam flow in the solar field. Most current steam generator designs use RC boiler designs, where water and steam exit the boiler section as a two-phase mixture. The steam mass fraction of the mixture - called the steam quality - is maintained to a desired value with a recirculation pump. At the outlet of the boiler section, dry steam is separated from the liquid and sent either to a super-heater section or to the turbine, and the saturated liquid returns to the inlet of the boiler section, as shown in Figure 2. The primary advantage of the RC configuration is the ability to ensure consistent heat transfer from the absorber to the fluid that prevents "burn-out", or severe local overheating. However, this arrangement requires steam separation equipment, return piping, 


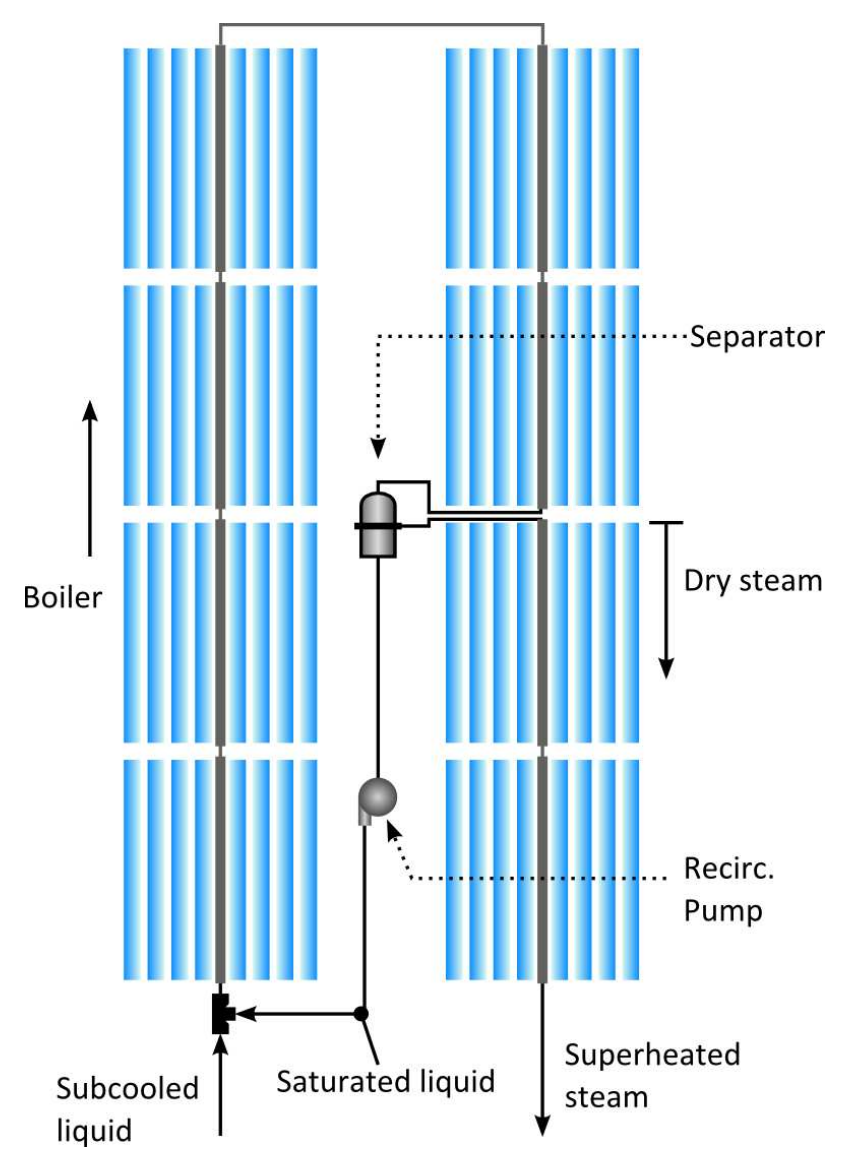

FIGURE 2. Schematic of a recirculated boiler loop with superheating. Liquid and steam are separated partway through the loop. This single loop is typically arranged in series with a number of similar loops.

and a recirculation pump that introduces additional cost and parasitic consumption.

An alternative to the RC design is once-through, so-called because the water is heated from its sub-cooled liquid state to superheat in a single pass through the loop. Benefits to the OT design are elimination of the steam separation and transport equipment, though this arrangement introduces the possibility of flow and heat transfer instability. OT flow has been proposed for linefocus CSP [21-23], but has not yet been demonstrated because of control complexity [24].

To facilitate performance comparison, the SAM LF model includes OT and RC options with super-heated steam. For RC systems, the user can specify the desired steam quality at the boiler outlet and the number of super-heater modules associated with the boiler section.

Receiver Type Linear Fresnel systems have been proposed with a variety of receiver types, including the trapezoidal cavity receiver shown in Figure 1 above, the solar-hotwater-derived receiver presented in Mills \& Morrison (2000), or the evacuated linear receiver for high temperature applications shown in Figure 3.

Because the receiver options can vary significantly in their thermal performance, SAM includes the ability to model both the high-performance evacuated tube receiver using a first-principles

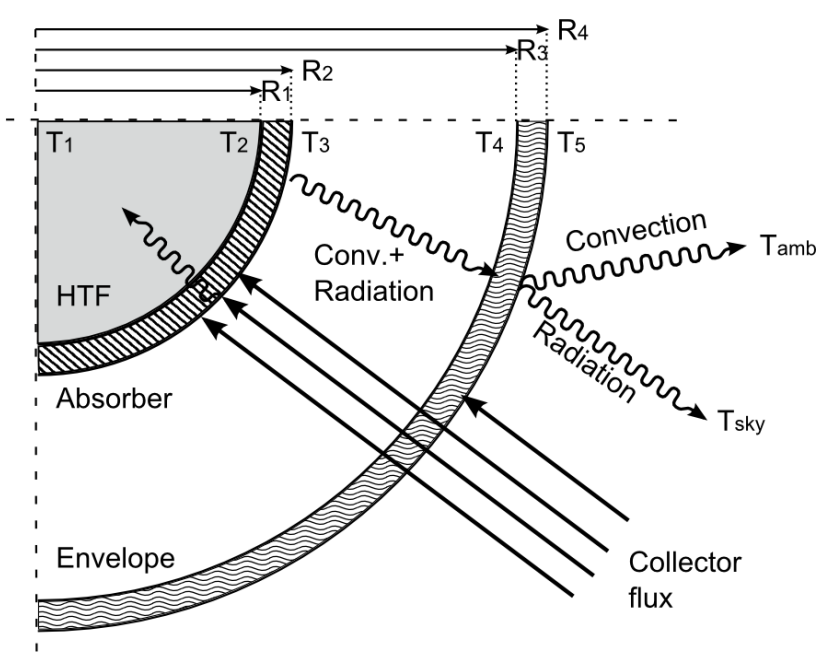

FIGURE 3. Evacuated tube receiver heat balance as modeled in SAM.

model described in [25] and adapted for the SAM Physical Trough model in [26], and a set of polynomial equations describing thermal performance as functions of load, local temperature difference, and wind velocity.

Auxiliary Fossil Integration Direct steam LF systems are not currently proposed with thermal storage, so one way for mitigating transients and extending the use of the power generation equipment is to integrate a fossil-fired backup system to provide heat. In systems where the outlet temperature from the solar field is difficult to maintain, fossil firing can also provide a mechanism for boosting the turbine inlet temperature to an acceptable level. SAM includes options for modeling three different fossil backup scenarios.

The first is "Minimum backup level", and refers to an auxiliary boiler in parallel with the solar field that supplies additional steam flow at design temperature when the solar field isn't able to supply the user-specified minimum operation level. The second option is "Supplemental operation" where additional flow (again, in parallel) is provided up to a user-specified maximum value to assist flow from the solar field to reach the design-point thermal requirement for the power cycle. These scenarios correspond to the plant arrangement shown in Figure 4 (top).

The final fossil backup scenario allows fossil firing up to a user-specified maximum thermal output to boost the temperature of steam entering the turbine. This option is shown in Figure 4 (bottom).

Detailed Cost and Financial Models Along with the performance model described above, the SAM LF model also includes integration with detailed cost and financial models for a set of applicable commercial and utility markets. The models provide realistic estimates of levelized cost of energy (LCOE) and other important metrics that capture a thorough range of project costs - both capital and financial. The financial models are presented in detail elsewhere [27]. 


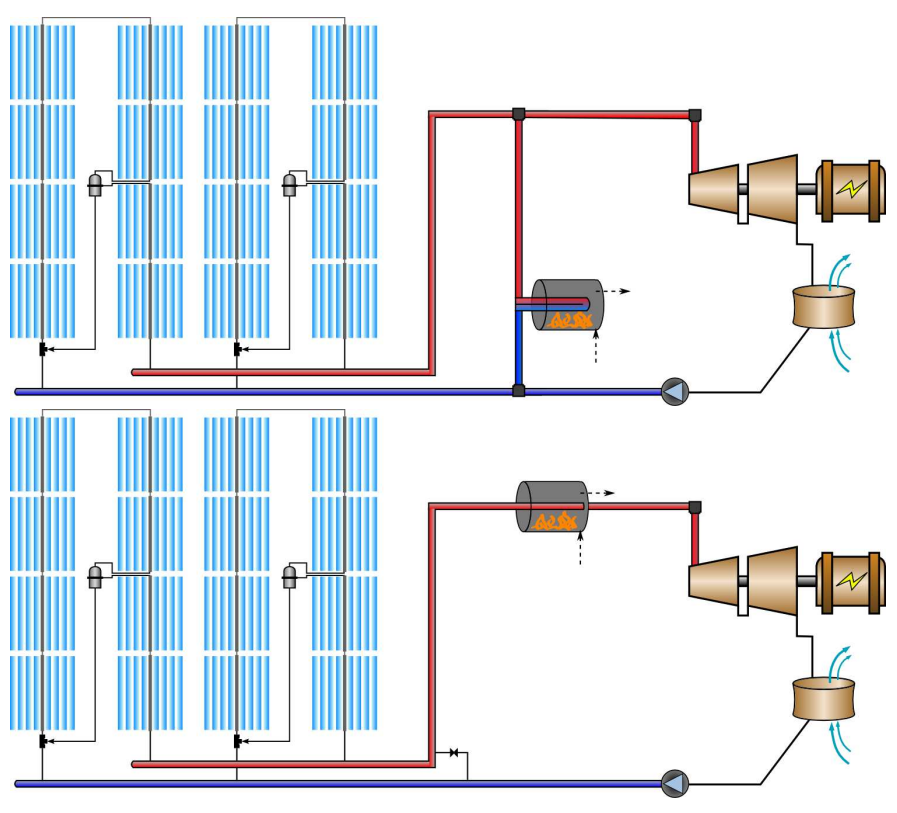

FIGURE 4. Plant arrangements for parallel auxiliary fossil backup (TOP) and series backup (BOTTOM).

\section{MATHEMATICAL DESCRIPTION}

The SAM LF model is broken into four major subsystem models - namely, the solar field, fossil auxiliary backup, the power block and heat rejection equipment, and the plant control algorithms. The most relevant features for each subsystem are discussed in more detail below.

\section{The Solar Field}

Solar field performance includes optical effects, thermal losses, and thermal inertia effects, all of which influence the total solar field performance. SAM allows the user to model these effects using several different approaches. This flexibility enhances the model's usability in a broader set of applications. The following subsections describe options for modeling optical and thermal performance in the solar field.

Field Energy Model From the point of view of the model, the solar field is segmented into a number of computational nodes where optical efficiency and thermal loss can be individually evaluated based on local steam conditions and collector geometry. Header piping feeds and collects steam flow from a number of parallel collector loops, and thermal losses are evaluated in the header piping according to a user-specified coefficient of thermal loss that scales with collector aperture area and average solar field temperature, as shown in Eq.[1]. Piping thermal losses are applied to the outlet flow from the solar field, reducing steam temperature according to the heat loss from piping.

$$
\dot{q}_{\text {piping }}=C_{h l}\left(T_{s f, a v e}-T_{a m b}\right) A_{s f, t o t}
$$

The performance of each computational node in the loop is evaluated in terms of energy absorbed $\left(\dot{q}_{a b s, i}\right)$, inlet and outlet enthalpy $\left(h_{\text {in }, i}\right.$ and $\left.h_{\text {out }, i}\right)$, and thermal transient effect. The absorbed energy term represents the total heat into the node after optical and thermal losses are considered. Heat loss is calculated using one of two receiver modeling methods discussed below, and the resulting thermal loss incorporates local steam temperature, ambient temperature, and wind velocity effects. The nodal energy balance is shown in Eq.[2], where $U_{\text {trans }, i}$ is the user-specified thermal inertia term (units of $\frac{k J}{K}$ ), $\bar{T}_{i}$ is the average temperature of the collector at node $i$ and $\bar{T}_{0, i}$ is the average temperature of the same node at the last time step, and $\Delta t$ is the time step duration in seconds.

$$
h_{\text {out }, i}=h_{\text {in }, i}+\frac{\dot{q}_{a b s, i}}{\dot{m}_{\text {steam }}}-\left(\bar{T}_{i}-\bar{T}_{0, i}\right) \frac{U_{\text {trans }, i}}{\Delta t}
$$

The solar field model evaluates the thermal performance of each node in series, sequentially applying the absorbed thermal energy to the steam flow. The method for controlling steam conditions varies depending on whether the solar field is OT or RC.

For RC systems, the mass flow rate in the boiler sections is iteratively varied to match the desired boiler steam quality. The mass flow of dry steam that is sent to the super-heater is constrained by the rate of steam generation in the boiler, and subsequent mass-flow-based temperature control for the super-heated steam is not physically possible. Consequently, the steam outlet temperature for RC systems will vary depending on time-of-day, solar irradiation conditions, and thermal losses.

For OT systems, mass flow can be iteratively varied throughout the loop such that the outlet steam temperature exactly matches the design-point value, within certain load constraints. SAM's ability to quickly resolve the performance of the solar field is due partially to custom high-performance steam property algorithms developed at the University of Wisconsin - Madison [28] for this and other projects. The steam property algorithms offer a significant performance improvement over RefProp [29] with comparable accuracy for this application.

Optical Performance Whereas the parabolic trough collector optical performance is a function of the incidence angle along the longitudinal plane of the collector (given a NorthSouth loop orientation), LF optical performance depends on both longitudinal and transversal plane incidence angles. This is conceptually illustrated in Figure 5, with the transversal incidence angle $\Phi_{T}$, longitudinal incidence angle $\Phi_{L}$, solar azimuth angle $\gamma_{s}$, and solar zenith angle $\theta_{z}$ shown. In this instance, the axis of the collector is parallel with the North-South line.

SAM allows the user to specify optical efficiency in one of three ways:

1. Solar position table: This option allows specification of the solar field optical efficiency as a function of solar azimuth $\gamma_{s}$ and zenith $\theta_{z}$ angles for a specific collector orientation. During each simulation time step, SAM calculates the solar position angles and interpolates within the table to determine the optical efficiency. If simulation of an alternate collector orientation is required, the table must be reformulated.

2. Collector incidence angle table: Like the solar position table, this option allows a table-based specification of optical efficiency. However, the table is expressed in terms of 


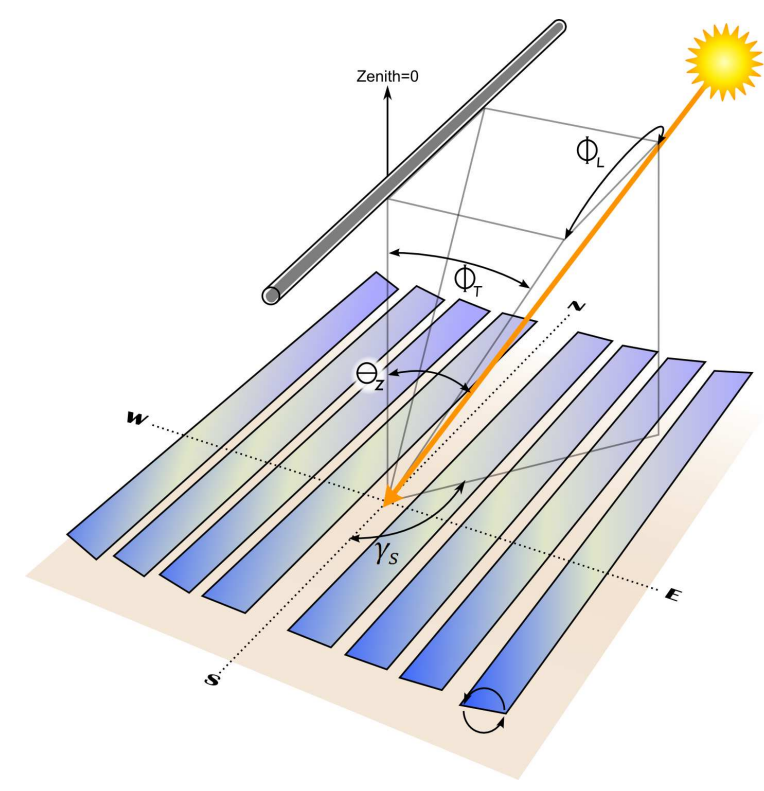

FIGURE 5. Illustration of the solar-position-dependent collector angles, including the transversal plane and longitudinal plane incidence angles. By convention, SAM assumes that the solar azimuth angle is $0^{\circ}$ South, with negative values toward the East and positive West.

transversal $\Phi_{T}$ and longitudinal $\Phi_{L}$ collector incidence angles.

3. Incidence angle modifier polynomials: The final option allows expression of the collector incidence angle modifiers as continuous polynomial equations. The user provides polynomial equation coefficients up to fourth order for the transversal and longitudinal incidence effects, and the results of each evaluated equation are multiplied to determine the final optical efficiency modifier.

Thermal Performance Thermal loss from the receiver tubing is a significant source of energy loss, second only to optical losses annually. As discussed previously, the receiver configuration can vary depending on the steam outlet conditions, performance requirements, and manufacturer. Because of this variation in receiver design, the SAM LF model was formulated in a general way to depend on local temperature difference between the steam and ambient air and on wind velocity. Each dependence is assessed in polynomial form, and the resulting values are multiplied to determine heat loss per meter of collector length. The general form for heat loss is:

$$
Y=\sum_{m=0}^{p} C_{m} X^{m}
$$

where $p$ is the order of the polynomial, $X$ is either local temperature difference $\left(T_{i}-T_{a m b}\right)$ or wind velocity $V_{\text {wind }}$, and $Y$ is the multiplicative factor adjusting the design-point receiver heat loss value specified by the user. The final thermal loss coefficient evaluated at each calculation node in the field is shown in Eq. [4].

$$
\dot{q}_{h l}=\sum_{i=1}^{N_{\text {modules }}} \dot{q}_{h l, i}=\sum_{i=1}^{N_{\text {modules }}} f_{h l, i}(\Delta T) \cdot f_{h l}\left(V_{\text {wind }}\right)
$$

Here, $f_{h l}(\Delta T)$ is the dimensional $(\mathrm{W} / \mathrm{m})$ heat loss as a function of local temperature difference and $f_{h l}\left(V_{\text {wind }}\right)$ is the nondimensional wind velocity adjustment factor.

SAM also provides an option to model receiver heat loss assuming an evacuated tube receiver as described in Forristall (2003). This flexibility allows the user to assess solar field conceptual designs that generate high-temperature steam. Furthermore, SAM's ability to model distinct geometries for the boiler and super-heater sections affords the possibility of modeling the lower-temperature boiler section with a more conventional receiver using the polynomial model and a high-temperature superheater section with the evacuated receiver model.

\section{Auxiliary Fossil Backup}

As mentioned above and illustrated in Figure 4, SAM includes three options for modeling the auxiliary backup integration. The user provides control factors based on a time-ofdispatch (TOD) schedule, where use of fossil backup can be allocated to certain months and hours of the year. The three different fossil operation modes use different criteria for dispatching auxiliary heat. The first option - Minimum Backup Level - provides enough energy from the fossil boiler to meet the non-dimensional load specified by the user during the current dispatch period.

$$
\dot{q}_{\text {aux }}= \begin{cases}\dot{q}_{p b, \text { des }} \cdot f_{\text {tod }}-\dot{q}_{s f} & \text { if } \dot{q}_{s f}<\dot{q}_{p b, \text { des }} \cdot f_{\text {tod }} \\ 0 & \text { if } \dot{q}_{s f} \geq \dot{q}_{p b, \text { des }} \cdot f_{\text {tod }}\end{cases}
$$

Here, $\dot{q}_{s f}$ is the thermal energy produced by the solar field during the current time step, $\dot{q}_{p b, \text { des }}$ is the design-point thermal load of the power block, and $f_{\text {tod }}$ is the TOD factor during the current time step.

The second option is Supplemental Operation, and allows fossil dispatch to supplement part-load steam flow from the solar field up to the specified fraction.

$$
\dot{q}_{a u x}= \begin{cases}0 & \text { if } \dot{q}_{s f} \geq \dot{q}_{p b, \text { des }} \\ \dot{q}_{p b, \text { des }}-\dot{q}_{s f} & \text { if } \dot{q}_{p b, \text { des }}-\dot{q}_{s f}<\dot{q}_{p b, \text { des }} \cdot f_{\text {tod }} \\ \dot{q}_{p b, \text { des }} \cdot f_{\text {tod }} & \text { if } \dot{q}_{p b, \text { des }}-\dot{q}_{s f} \geq \dot{q}_{p b, \text { des }} \cdot f_{\text {tod }}\end{cases}
$$

The final option is Topping Mode. Unlike the previous two options that operate the auxiliary boiler in parallel with the solar field, Topping Mode places the boiler in series with the solar field, "topping off" the steam exiting the solar field to maintain desired temperature conditions as it enters the turbine. The energy supplied to the fluid follows the same conventions as the Supplemental Operation mode shown in Eq.[6], but the calculation for final enthalpy into the turbine is modified to reflect the additional energy. 


\section{The Power Cycle \& Parasitic Consumption}

The SAM LF model is based on a performance regression model based on the cycle described in [30], but includes modifications to accommodate the direct-steam configuration (as opposed to indirect heat exchange between the steam working fluid and a sensible-heat HTF). This model is described in detail elsewhere [31], but uses a multiple linear regression model to determine power cycle performance as a function of condenser pressure (via ambient temperature), thermal load, and turbine inlet temperature.

The model accounts for several different parasitic electricity draws, including collector field tracking drives, feedwater pumps, heat rejection pumps and fans, fixed parasitics for plant lighting, control, and site operation, and parasitics associated with operation of the auxiliary fossil equipment (if applicable). The most prominent parasitic draw is from the heat rejection equipment, and the remaining items exhibit similar requirements depending on the operation mode.

The feedwater pumping requirement depends significantly on the pressure drop across the solar field. This quantity is difficult to evaluate from first principles within an annual-hourly model given the complexity of LF receiver geometry, the twophase flow conditions, and the lack of publicly available data for this technology. For these reasons, the SAM LF model employs a set of user-specified pressure drop values that are scaled relative to design point operation according to the normalized mass flow rate in the solar field and turbine.

For a fixed piping length of known diameter, pressure drop of a liquid scales with mass flow as:

$$
\Delta P=C_{0} \Delta P_{r e f}\left(\frac{\dot{m}_{s f}}{\dot{m}_{s f, d e s}}\right)^{C_{1}}
$$

where straight piping lengths typically have power coefficients $C_{1}$ near 1.9. However, because the pressure drop model doesn't make any assumptions about piping diameter, phase change behavior, or fluid velocity at design, SAM scales the pressure drop linearly as a function of mass flow rate such that:

$$
\Delta P=\Delta P_{r e f}\left(\frac{\dot{m}_{s f}}{\dot{m}_{s f, d e s}}\right)
$$

This approximation is generally conservative (i.e. it overestimates pressure drop and pump parasitic consumption at partload operation). The user can estimate the performance of a variety of loop piping configurations with the pressure drop values, including loops where separation equipment is present between the boiler and superheater portions and solar field that have separate boiler and superheater loops with centralized steam separation equipment.

\section{CASE STUDY - FIELD CONFIGURATIONS}

The various performance analysis capabilities discussed previously in this paper are demonstrated with a case study that investigates the effects of RC and module configuration. The study
TABLE 1. Case study system features.

\begin{tabular}{l|c|c} 
Item & Units & Value \\
\hline Location & - & Daggett, CA \\
Net power rating & MWe & 100.6 \\
Net design cycle efficiency & $\%$ & 38.0 \\
Solar multiple & - & 1.75 \\
Field aperture area* & $\mathrm{m}^{2}$ & 846,412 \\
Collectors per loop* & - & 16 \\
Field outlet temperature & ${ }^{\circ} \mathrm{C}$ & 440 \\
Design irradiation & $\mathrm{W} / \mathrm{m}^{2}$ & 950 \\
Design-point field pressure drop & $\mathrm{bar}$ & 20 \\
Cooling type & - & Dry \\
$\quad$ * Varies by case & &
\end{tabular}

assumes a 107 MWe (gross) power block with no fossil backup. Major plant features are summarized in Table 1.

The baseline system is a RC boiler solar field with 16 modules per collector loop. The steam mass flow rate in the $\mathrm{RC}$ boiler is constrained to exit at $75 \%$ quality (steam mass fraction), and the separated dry steam passes through the four superheater modules.

Since the rate of evaporation in the boiler is strictly a function of the thermal power reflected to the receiver, the mass flow rate of dry steam into the superheater is constrained for the RC system. Consequently, steam outlet temperature varies depending on operating conditions. Figure 6 shows solar field outlet temperature and the steam temperature delivered to the power block (after piping thermal losses) for several days in winter.

Note in Figure 6 that the actual steam temperature into the power block is noticeably higher than the design-point value of $440^{\circ} \mathrm{C}$. This demonstrates the dependence of steam outlet conditions for the RC system on collector geometry and operating conditions rather than control of the mass flow rate. This concept is further demonstrated when the number of superheater modules is increased from 4 to 5 , giving a total of 17 collector modules per loop. The results of this case are shown in Figure 7.

Collector geometry loses its impact on steam conditions in the OT configuration, since mass flow can be modulated to achieve the desired steam outlet temperature, as shown in Figure 8.

Several other results of interest are presented in Table 2 on an annual basis. As expected, the annual pumping parasitic requirement is lower for the once through system than for the $\mathrm{RC}$ systems, though pumping power is minuscule in comparison to net electricity production. Another interesting outcome in comparing the baseline RC system to the RC system with an additional superheater section is that power production is reduced in the higher-temperature configuration. This is caused by an increase in receiver thermal losses that is not overcome by the cycle efficiency improvement.

The analysis results demonstrate the motivation for moving to OT steam flow. In comparison to the RC system, the OT configuration shows reduced annual heat loss, reduced pumping power requirement, and better temperature control at the superheater outlet. In avoiding recirculation of saturated liquid, the bulk fluid temperature throughout the boiler section is reduced 


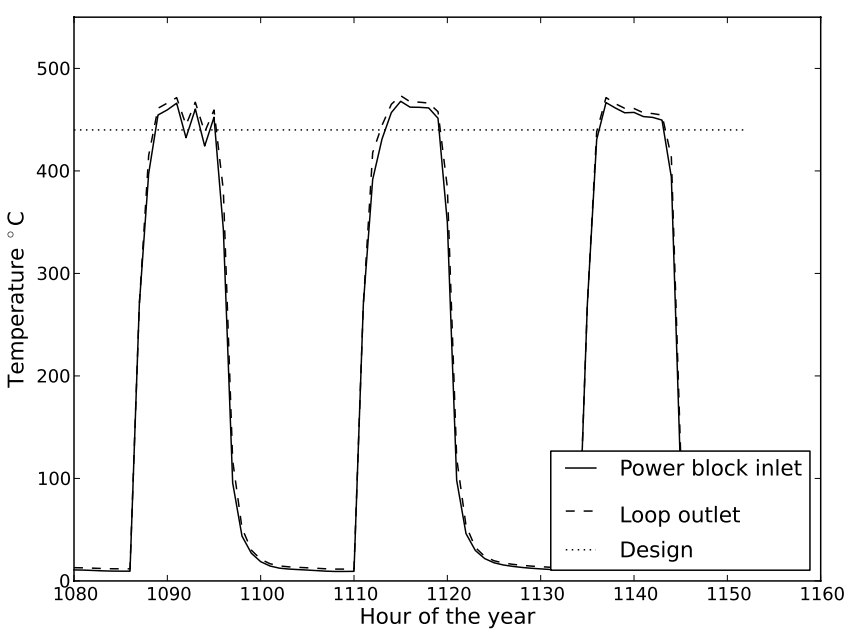

FIGURE 6. Steam temperature at the outlet of the solar field and inlet to the power block for the baseline recirculated system.

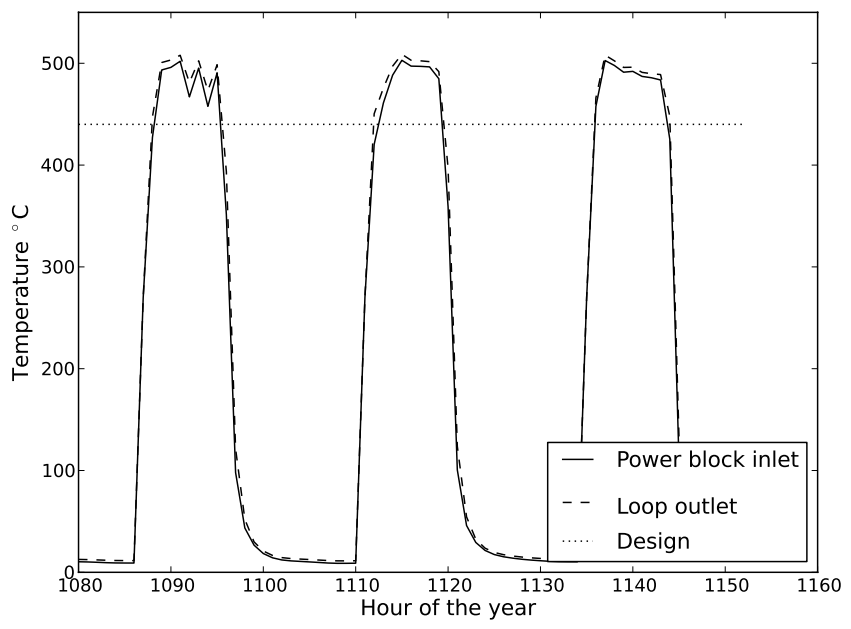

FIGURE 7. Steam temperature for the recirculated system with an extra superheater module.

TABLE 2. Summary of annual output results for the three cases - recirculated baseline $(\mathrm{RC})$, recirculated with an extra superheater module $(\mathrm{RC}+1 \mathrm{SH})$, and once-through (OT).

\begin{tabular}{l|c|rrr} 
Item & Units & $\mathbf{R C}$ & $\mathbf{R C}+\mathbf{1 ~ S H}$ & OT \\
\hline Total incident energy & MW & $2,362,697$ & $2,364,130$ & $2,362,697$ \\
Dumped energy & MW & 83,072 & 81,544 & 86,207 \\
Total thermal losses & MW & 128,514 & 135,513 & 125,590 \\
Total pumping power & MW & 505 & 515 & 443 \\
Gross energy output & MW & 242,487 & 238,135 & 242,700 \\
Net energy output & MW & 228,050 & 223,689 & 228,170 \\
Capacity factor & $\%$ & 25.9 & 25.4 & 25.9
\end{tabular}

since the loop inlet operates at the feedwater temperature and not at the mixed feedwater/recirculation temperature. The lower mass flow rate in the boiler also reduces pumping parasitic consumption.

Equivalent performance for the OT and RC system further lend the OT configuration preference when considering the re-

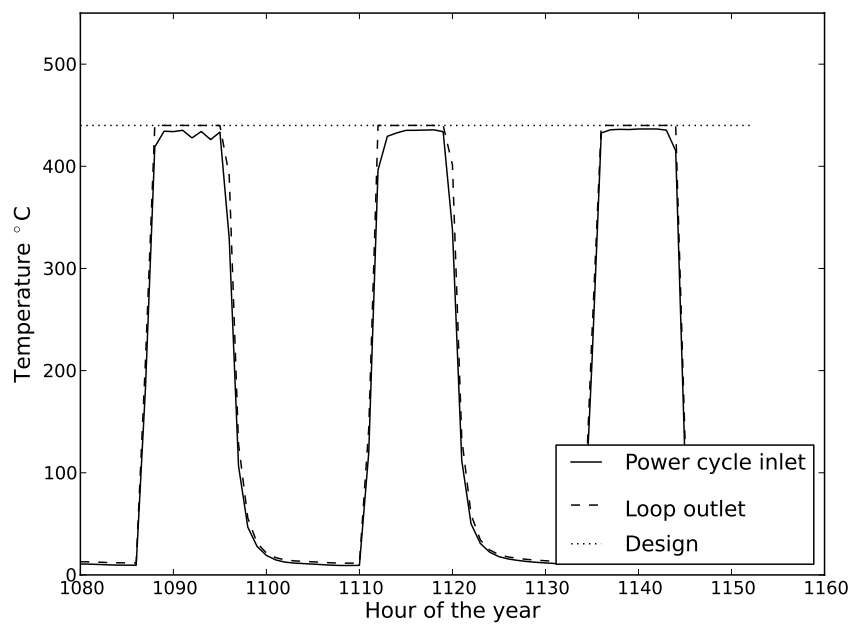

FIGURE 8. Steam temperature for the once-through system.

duced equipment cost. Recirculation requires a phase separator, a recirculation loop pump, and additional piping and valving for returning saturated liquid from the separation point to the collector inlet. The temperature stability at the outlet of a OT field reduces the need for attemporation equipment and reduces the extremes of thermal cycling on piping and turbomachinery, which can lead to reduced operation and maintenance cost later in the plant's life.

However, flow stability in OT systems remains a serious concern and must be successfully managed before commercial adoption of this configuration.

\section{CONCLUSIONS AND OUTLOOK}

This paper presents a new DSG Linear Fresnel modeling tool for SAM that is capable of predicting annual output, hourly performance, and economic project return. The major features of the model are presented and discussed along with a case study to demonstrate functionality. Based on extensive review of previously developed models, this tool is shown to contribute to the current public modeling capability in a new way.

Future work will augment the model to include systems with sensible-heat fluids and thermal storage as high-temperature systems have been proposed [32] and are under consideration for development at NREL. Additional work will also focus on providing tools for rapid characterization of LF collector optics, including wizards for collector geometry layout. This work will facilitate high-temperature LF system development with the goal of meeting the US DOE's SunShot program cost goal of $6 \phi / \mathrm{kW}$ hr by 2020 .

\section{ACKNOWLEDGMENTS}

Development of the Linear Fresnel model was funded by the Electric Power Research Institute (EPRI) through Cooperative Research and Development Agreement WRE5-11-430 and by the US Department of Energy. The authors thank Camille Bachelier and Christian Paul of Novatec Solar (Germany) for their role in technical review and validation of the performance 
model.

\section{REFERENCES}

[1] EPRI, 2009. Solar Thermal Hybrid Demonstration Project at Pulverized Coal Plant.

[2] Morin, G., Dersch, J., Platzer, W., Eck, M., and Häberle, A., 2011. "Comparison of Linear Fresnel and Parabolic Trough Collector power plants". Solar Energy, 86, July, pp. 1-12.

[3] Gilman, P., National Renewable Energy Laboratory (US), and Sandia National Laboratories, 2008. Solar advisor model user guide for version 2.0.

[4] Goswami, R., Negi, B., Sehgal, H., and Sootha, G., 1990. "Optical designs and concentration characteristics of a linear Fresnel reflector solar concentrator with a triangular absorber". Solar Energy Materials, 21(2-3), Dec., pp. 237251.

[5] Abbas, R., Montes, M., Piera, M., and Martínez-Val, J., 2012. "Solar radiation concentration features in Linear Fresnel Reflector arrays". Energy Conversion and Management, 54(1), Feb., pp. 133-144.

[6] Abbas, R., Muñoz, J., and Martínez-Val, J., 2012. "Steadystate thermal analysis of an innovative receiver for linear Fresnel reflectors". Applied Energy, 92, Apr., pp. 503-515.

[7] Facão, J., and Oliveira, A. C., 2009. "Numerical simulation of a linear Fresnel solar collector concentrator". In 8th International Conference on Sustainable Energy Technologies, no. September, pp. 2-7.

[8] Flores Larsen, S., Altamirano, M., and Hernández, a., 2012. "Heat loss of a trapezoidal cavity absorber for a linear Fresnel reflecting solar concentrator". Renewable Energy, 39(1), Mar., pp. 198-206.

[9] Pye, J. D., 2008. "System Modelling of the Compact Linear Fresnel Reflector". PhD thesis, University of New South Wales.

[10] Reynolds, D., 2004. "An experimental and computational study of the heat loss characteristics of a trapezoidal cavity absorber". Solar Energy, 76(1-3), Mar., pp. 229-234.

[11] Mills, D. R., and Morrison, G. L., 2000. "COMPACT LINEAR FRESNEL REFLECTOR SOLAR THERMAL POWERPLANTS". Solar Energy, 68(3), pp. 263-283.

[12] Klein, S., 1979. TRNSYS, A transient system simulation program.

[13] Häberle, A., Zahler, C., Lerchenmüller, H., Mertins, M., Wittwer, C., Trieb, F., and Dersch, J., 2002. "The Solarmundo line focussing Fresnel collector. Optical and thermal performance and cost calculations". In Proceedings of the 2002 SolarPACES International Symposium.

[14] Gharbi, N. E., Derbal, H., Bouaichaoui, S., and Said, N., 2011. "A comparative study between parabolic trough collector and linear Fresnel reflector technologies". Energy Procedia, 6, Jan., pp. 565-572.

[15] Giostri, A., Binotti, M., Silva, P., Macchi, E., and Manzolini, G., 2011. "COMPARISON OF TWO LINEAR COLLECTORS IN SOLAR THERMAL PLANTS: PARABOLIC TROUGH VS FRESNEL". In Proceedings of the ASME 2011 International Conference on Energy
Sustainability.

[16] Dersch, J., Schwarzbözl, P., and Richert, T., 2011. “Annual Yield Analysis of Solar Tower Power Plants With GREENIUS”. Journal of Solar Energy Engineering, 133(3), p. 031017.

[17] Wittwer, C., Hube, W., Schossig, P., Wagner, A., Kettner, C., Mertins, M., and Rittenhofer, K., 2001. "ColSim - A NEW SIMULATION ENVIRONMENT FOR COMPLEX SYSTEM ANALYSIS AND CONTROLLERS”. In Seventh International IBPSA Conference.

[18] Thermoflow Inc., 2012. Thermoflow modeling software, www.thermoflow.com.

[19] Dersch, J., 2010. greenius User Manual. Tech. rep., DLR, Köln, Germany.

[20] Dersch, J., Hennecke, K., and Quaschning, V., 2010. "Greenius - a simulation tool for renewable energy utilization”. In Proceedings of the 2010 SolarPaces International Symposium.

[21] Lippke, F., 1996. "Direct steam generation in parabolic trough solar power plants: Numerical investigation of the transients and the control of a once-through system". Journal of Solar Energy Engineering, 118(1), Feb.

[22] Odeh, S., Behnia, M., and Morrison, G., 2000. "Hydrodynamic analysis of direct steam generation solar collectors". Journal of solar energy engineering, 122(February), p. 14.

[23] Eck, M., and Hirsch, T., 2007. "Dynamics and control of parabolic trough collector loops with direct steam generation". Solar Energy, 81(2), Feb., pp. 268-279.

[24] Zarza, E., Valenzuela, L., León, J., Hennecke, K., Eck, M., Weyers, H.-D., and Eickhoff, M., 2004. "Direct steam generation in parabolic troughs: Final results and conclusions of the DISS project”. Energy, 29(5-6), Apr., pp. 635-644.

[25] Forristall, R., 2003. Heat Transfer Analysis and Modeling of a Parabolic Trough Solar Receiver Implemented in Engineering Equation Solver. Tech. Rep. October, National Renewable Energy Laboratory, Golden, CO.

[26] Wagner, M. J., and Gilman, P., 2011. Technical Manual for the SAM Physical Trough Model. Tech. Rep. June, National Renewable Energy Laboratory, Golden, CO.

[27] National Renewable Energy Laboratory, 2012. https://sam.nrel.gov/financial.

[28] Dyreby, J., 2011. Steam Code - Northland Numerics. Personal Communication.

[29] Lemmon, E. W., Mclinden, M. O., and Huber, M. L., 2002. NIST Reference Fluid Thermodynamic and Transport Properties REFPROP. Tech. rep., NIST.

[30] Wagner, M. J., 2010. "Methodology for Constructing Reduced-Order Power Block Performance Models for CSP Applications Preprint”. In SolarPACES 2010, no. October.

[31] Neises, T., and Wagner, M. J., 2012. "Annual Simulation of Direct Steam Power Tower Concentrated Solar Plant Preprint". In Proceedings of the ASME 2012 6th International Conference on Energy Sustainability \& 10th Fuel Cell Science, Engineering and Technology Conference.

[32] Grena, R., and Tarquini, P., 2011. "Solar linear Fresnel collector using molten nitrates as heat transfer fluid". Energy, 36(2), Feb., pp. 1048-1056. 